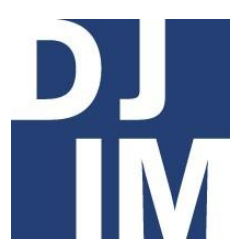

Volume 14

Spring

2018

djim.management.dal.ca |

\title{
The Language of Cataloguing: Deconstructing and Decolonizing Systems of Organization in Libraries
}

Crystal Vaughan

School of Information Management, Dalhousie University

\begin{abstract}
This paper analyzes the language of cataloguing because the information that librarians and other information professionals provide to others has a huge impact both on how others are viewed and how others view themselves. This ultimately comes down to the way in which words are given meaning and interpreted according to the socio-political climate of the time. As society, politics, and economies change, so too does the language of representation. Therefore, the Library of Congress subject headings (LCSH) as a system of categorization is only as effective as the language that is used to define what is and what is not. Moreover, those who control the language of categorization control access to the information categorized within that system. Consequently, librarians must always be critical of the language they are using in their information organization systems. Language is continuously evolving according to societal discourse and politics; therefore, if libraries are to maintain their social responsibility to provide information to all, including socially disadvantaged and marginalized peoples, then librarians must continuously advocate for changes to subject headings. Librarians must also recognize and reflect on their own internal biases when cataloguing and make it their job to deconstruct language and decolonize the systems that perpetuate the continued marginalization of others. To remain neutral about these systems is the very opposite of what it means to be a librarian in the twenty-first century.
\end{abstract}




\section{Introduction}

The classification of things, also known as taxonomy, is fundamental to how systems of language work. Words classify objects and concepts and, according to Noam Chomsky, universal grammar organizes these words into different classifications (White, 2003). Classification, however, although necessary in systems of language, contributes to hierarchies of power: the power to define information and the power to grant or limit access to that information.

The Library of Congress, the largest library in the modern world (Hayden, 2017), uses an extensive classification system called the Library of Congress Classification (LCC) to categorize and organize its library catalogue. The Library of Congress Subject Headings (LCSH) - a thesaurus of controlled vocabulary - is used not only by the Library of Congress, but also by libraries across the world. However, there have been many criticisms about the LCSH - some of which this paper will address - because a system of categorization is only as effective as the language that is used to define terms in every day speech. Language is continuously evolving according to societal discourse and politics. Consequently, many libraries are members of the Subject Authority Cooperative Program (SACO), which accepts proposals for additions and changes to the LCSH (Library of Congress, n.d.). Despite the many changes that have been implemented in the $\mathrm{LCSH}$, there are still many LCSH that marginalize and dehumanize vulnerable, disadvantaged, and/or minority populations, which therefore restricts their access to information. If libraries are to maintain their social responsibility to provide information to all, including socially disadvantaged and marginalized peoples (IFLA, 2012), then librarians must continue to advocate for changes to politically charged or controversial subject headings.

\section{History of Library Classification Systems}

Although humans have always needed to organize and classify information for communication and survival, systems of information management, such as what we see in a library, did not develop until the advent of writing, circa 3000 BC (Rubin, 2015). Rubin (2015) explains that ancient Sumerian clay tablets, which recorded information about Sumerian society and commerce, were kept and managed by a high-ranking official called the "keeper of the tablets" (p. 32). Tablets were tagged or kept in boxes, which were then itemized with a "tablet of contents" (Rubin, 2015, p. 32). Libraries and systems of organization have come a long way from clay tablets, but these "tablets of contents" (Rubin, 2015, p. 32) were simply just a primitive type of subject heading - a system of categorization that allows for information retrieval. Until the invention of the printing press, written information was only available to select individuals (Rubin, 2015), but once the printing press made written information available to the masses, systems of information management and 
classification needed to become more sophisticated to handle the breadth of information available. Ingrid Parent (2015) explains that information retrieval, such as cataloguing, "became more compartmentalized, logical, hierarchical, and controlled" (p. 703). The rapid advancement of technology and the advent of digital information has made classification systems even more sophisticated, and yet cataloguing - which uses an organization system of subject headings - is still compartmentalized and based on hierarchy and control. Although hierarchical division is a linguistic necessity for classifying concepts in a logical framework, they can also reflect societal power structures.

\section{Language as Representation}

The controlled vocabulary that makes up subject headings states exactly what it is: a controlled, and therefore, rigid language. These controlled vocabularies, as Emily Drabinski (2013) argues, "reduce and universalize language" (p. 94), which results in marginalizing other interpretations because language systems are representative rather than definitive. French philosopher Jacques Derrida (1986) explains in "Différance" that "in the system of language, there are only differences" ( $p$. 404). He theorizes that meaning is not inherent in a particular word or signifier and that the representation of something lacks authority because it can only be defined by its absence. Words, therefore, can never fully express true meaning. There

The Language of Cataloguing is always a gap or a void between the signifier and the signified. Derrida (1986) says this "constrains us-as inhabitants of a language and a system of thought-to formulate the meaning of Being in general as presence or absence" (p. 402). The (sign)al representative of being, or "to be," is not actually being. Although language cannot represent being, we define ourselves through the binary of presence and absence, one or the other: we are what something else is not.

Toni Weller (2007) explains that throughout history the categorization of information and how it is perceived and applied, "is or was affected by, the social, political, economic and cultural climates of the time" (p. 438). Consequently, when classifications are created, they inherently reflect the predominant biases of society (Hajibayova \& Buente, 2017). To categorize something is to define what it is not, yet what something is or is not is subject to change depending on the socio-political climate. Consequently, representation is a fluid construction. A signifier that represents a thing is never static because presence and absence frequently changes depending on the various factors that influence it. Furthermore, the representation of being in one language may not be fully translatable to another language (Hajibayova \& Buente, 2017), which means that something is often lost in the translation of representation, resulting in a distorted meaning. These socio-political, economic, and cultural biases in categorization, therefore, also affect library subject headings. 
This is certainly not a new realization. William Benemann wrote in 1987 that the history of America was written by cataloguers because subject headings "provide a window on American society, a naive [sic] splattering of images that may well tell us more about ourselves that we could learn from 21 linear feet of statistical data" (p. 650). Although the language we use to categorize things and concepts has changed with the socio-political climate, subject headings that describe sociallydisadvantaged peoples and minority cultures have mostly remained static. This has resulted in much criticism because the language of subject headings continues to marginalize and colonize minorities, such as: people of colour, Indigenous peoples, women, LGBTQ+ communities, people with disabilities, and other cultures or belief systems that were not recognized or accepted in the past. Traditionally, libraries have claimed that subject headings are neutral (Farkas, 2017), but critical analysis of mainstream subject headings shows that this is not the case. Since taxonomies reflect the socio-political climate and prescribed language of their times, "classifications are inherently biased" (Adler, 2016, p. 630). Due to the Western colonization and the subjugation of peoples or cultures seen as lesser or uncivilized, subject headings are primary constructed from a Western viewpoint (Parent, 2015).

\section{Cataloguing Representation}

A movement to change library organization systems, such as the LCSH, to address whitewashing, began with U.S. librarian Sanford Berman in the early 1970s (Drabinski, 2013). While working in Zambia he discovered that U.S. cataloguers were using a term in libraries that was derogatory towards black Africans (Drabinski, 2013). Berman realized that "where and when and by whom subject headings are used makes all the difference in terms of meaning" (Drabinski, 2013, p. 95). In 1971, Berman wrote that LCSHs:

$$
\begin{aligned}
& \text { can only "satisfy" parochial, } \\
& \text { jingoistic Europeans and North } \\
& \text { Americans, white-hued, at least } \\
& \text { nominally Christian (and preferably } \\
& \text { Protestant) in faith, comfortably } \\
& \text { situated in the middle- and higher- } \\
& \text { income brackets, largely domiciled } \\
& \text { in suburbia, fundamentally loyal to } \\
& \text { the Established Order, and heavily } \\
& \text { imbued with the transcendent, } \\
& \text { incomparable glory of Western } \\
& \text { civilization. (Drabinski, 2013, p.99) }
\end{aligned}
$$

The LCSH list, Berman argued, did not represent anything outside the confines of what was strictly defined by Western culture. Berman, and other like-minded librarians, thus began a crusade to rectify this problem (Drabinski, 2013, p. 95).

Although Berman and others have been successful in changing many LCSHs, as previously mentioned, biases still exist, and will always exist in taxonomies because 
cultural climates are frequently shifting and language will always maintain a shifting Derridian gap between sign and signifier. Furthermore, as Emily Drabinski (2013) argues corrections to the catalogue, such as Berman's, "are always contingent and never final, shifting in response to discursive and political and social change" (p. 100). It is impossible to close the gap between words and meaning, and between present and future socio-political systems. Consequently, corrections to any subject heading list will never be final and will always be a work in progress. Cataloguing representation, therefore, should be less about using the "correct" language and more about locating and addressing colonial ideologies that still exist in our society (Drabinski, 2013).

Changing subject headings has never been an easy task for cataloguers. During the time of card catalogues, librarians had to weigh the costs and benefits (El-Hoshy, 1998, p. 201). Changing subject headings to reflect the current vernacular is necessary to ensure that patrons will be able to retrieve the information for which they are searching. However, updating card catalogues at the Library of Congress and across American libraries was a costly and time-consuming activity. El-Hoshy (1998) states, for example, that the decision to change the outdated term "Water-closets" to "Toilets" did not happen until the 1970s, long after toilets became the preferred term in everyday speech. Now that card catalogues are digital, and have been since the mid-1980s with the invention of The Language of Cataloguing
Machine-Readable Cataloging (MARC) records (Parent, 2015), the physical tasks involved in updating subject headings is easier (El-Hoshy, 1998). Still, Gayle Osterberg, the current Library of Congress Director of Communications, explains that the process of changing subject headings can still take anywhere between two and six months (Peet, 2016). In addition, changing controversial subject headings can come with quite a lot of resistance because, not only is language fluid, it is also powerful. Those who control language, and therefore control classifications, have power over the access and dissemination of information. Consequently, those who control language can either make reparations towards marginalized peoples or continue to perpetuate colonial discourse, which is why advocating for change to the LCSH is important, despite the challenges.

\section{No Human is Illegal: A Case Study}

A recent example where the language of subject headings was used as means to maintain power in socio-political discourse involves Melissa Padilla, a student at Dartmouth College in New Hampshire, U.S. Padilla has been petitioning the Library of Congress since 2014 to change the term "illegal alien" in the LCSH system (Aguilera, 2016, para. 3-4). This LCSH has already been through two revisions because the word "alien" has different meanings and is mostly used to refer to beings from outer space (Peet, 2016, para. 4). The subject 
heading was changed to "Aliens, illegal" in 1980, and then to "illegal aliens" in 1993 (Peet, 2016, para. 4). Padilla wants this subject heading changed again because she argues that the term is derogatory, dehumanizing (Peet, 2016), and "criminalize[s] the choices our parents made in order to provide us with better lives" (Aguilera, 2016, para. 2). In other words, no human should be described as illegal.

In 2016, after some debate between the Library of Congress and the American Library Association about finding an appropriate term synonymous with the meaning behind illegal alien (Peet, 2016), the Library of Congress agreed to replace the term with "noncitizen" and "unauthorized immigration" (Peet, 2016, para. 12). The term "illegal alien" would be cross-referenced with the new terms so that anyone searching for the outdated term would still able to retrieve the information classified under the new terms (Peet, 2016). However, before the Library of Congress had the chance to update the LCSH, Republican lawmakers introduced provision HR 4926, named the "Stopping Partisan Policy at the Library of Congress Act," into a bill that dealt with funding of public institutions like the Library of Congress (Peet, 2016). This provision, which was passed on June 10, 2016, required the Library of Congress to keep "illegal alien" as a subject heading (Peet, 2016).

The justification for halting the LCSH change was that the term "illegal alien" is still used in U.S. federal law (Aguilera, 2016). However, other derogatory or outdated terms found in long-standing laws have since been updated by cataloguers without government interference. The fact that this provision was placed in a bill that addresses the funding of institutions like the Library of Congress was a less than veiled threat to the library, and suggested that the reason was more about politics than about immigration laws. The politics behind this Republican backlash are also illustrated by what the bill's sponsor, Republican representative Diane Black, said about the provision. She argued that the Library of Congress was "trading common-sense language for sanitized political-speak," which does not address "the grave threat that illegal immigration poses to our economy, our national security, and our sovereignty" (Peet, 2016, para 17). Black's rhetoric that illegal immigration is a threat to United States citizens' way of life demonstrates that those with the power to control language can subjugate alternative discourse.

Black's justifications for government lawmakers meddling with the Library of Congress' system of information management have not gone unchallenged. Democratic representative, Debbie Wasserman Schutz, disagrees with Black, stating that the "LC should be able to make taxonomic decisions outside of the political arena" (Peet, 2016, 19). According to Osterberg, this is the first time that government became involved with changes

The Language of Cataloguing 
in the library's taxonomy (Aguilera, 2016). Osterberg explains that the Library of Congress adds upwards of five thousand new subject headings to the LCSH each year (Peet, 2016), and frequently reviews and revises outdated subject headings "to make sure that we're keeping current with the language that researchers are using" (Peet, 2016, para 14). This illustrates that, even though the current political climate in the United States demonstrates an unwillingness to acknowledge social injustices and the people left marginalized by dehumanizing and pejorative language, it may not always be so. Padilla has lost her fight to have the term "illegal aliens" changed in the LCSH for the moment, but a change in political leadership in the future may give her argument new breath.

\section{Naming An(Other)}

Even when subject headings are updated using the current socially acceptable or "correct" terminology, these terms still fall into the Derridian gap between representation and meaning. The representation or categorization of one thing separates that thing from something else, creating a boundary: an other. Consequently, the other is automatically categorized as something that is not representative of the first representation (Drabinksi, 2013). Drabinski (2013) uses the subject heading "Lesbian" as an example. "Lesbian" is an accepted term in the LGBTQ+ community, but it does "not account for all the other words users might use to describe themselves" (p. 95). Words do not, and cannot, convey accurate or complete representation. Instead, as Drabinksi (2013) explains, they give "potential identities [that] users can either claim as true and authentic representations of themselves or resist as not quite correct" (p. 102). Therefore, subject headings that represent social, cultural, or political identity will always be a site of controversy and resistance (Drabinski, 2013). What is socially acceptable now may not be in the future.

Furthermore, language cannot be fixed in place because human experience and knowledge is not universal to all peoples or cultures (Drabinski, 2013). For example, the United Nations states there are four to five thousand different and culturally distinct Indigenous cultures around the world, and yet these cultures are placed under the umbrella term, "Indigenous peoples" (Adler, 2016). The communities and individuals that are categorized under this term did not choose to be called "Indigenous." Nor did they choose any of the previously socially acceptable terms that came before, such as Aboriginal, First Nations, Native, American Indian, etc. These terms were given to them without consultation. Each of these thousands of cultures have their own names and identities separate from the blanket description of "Indigenous" (Adler, 2016), which further demonstrates that the naming or categorization of an(other) can never give a true representation. Moreover, grouping these different cultures together 
under an umbrella term gives legitimacy to their marginalization (Adler, 2016).

Naming other cultures also grants authority to the majority culture that had the power to name them because, as Hope A. Olson (2002) explains that naming "control[s] the subject representation and, therefore, access" (Hajibayova \& Buente, 2017, p. 1140). Naming creates an(other)'s identity by imposing experiences and reality onto a group of individuals (Hajibayova \& Buente, 2017). Although replacing offensive terms with something viewed as more politically correct is always meant with good intentions, naming an(other) participates in what Lala Hajibayova and Wayne Buente (2017) describe as "the greater colonial logic of assimilation" (p. 1141). In order to decolonize marginalized peoples and cultures, these cultures must be invited to participate in naming themselves so that they can be properly represented in organizational systems.

Not only should library subject headings and representations be critiqued, but so should classification hierarchies within library organization systems. Often when subject headings are changed to something more socially acceptable, the classification hierarchies (and therefore the location) of the information are not (Adler, 2017). Library classification systems such as the LCC are not critiqued as much as subject headings. Drabinski (2016) thinks this is probably because subject headings allow patrons to search and access information, whereas classifications are usually viewed as a shelf address (p. 99). But not only have cataloguers placed their own socio-political biases in subject headings, those who created the LCSH have also done so with regards to the placement of materials in the library (Drabinski, 2013). For example, a book about transgenderism given a class number next to a book about mental illness illustrates the initial classifier's ideological biases. The relation of these books to each other tells a story to the patron browsing the shelves that is both inaccurate and harmful, and is likely to propagate fear and prejudice.

Humans are fallible, so biases in classification can never be removed entirely. However, the library system will continue to fail patrons if librarians do not work to deconstruct their biases about marginalized peoples and cultures (Drabinski, 2013, p. 97). Drabinski (2013) argues that,

as a result of these failures, biased ideological stories continue to be "told" by the organizational systems. As users interact with these structures to search, browse and retrieve materials, they inevitably learn negative stereotypes about race, gender, class, and other social identities. (p. 97)

In addition, although the Library of Congress is willing to replace subject headings when someone makes a good case for it (and when the government does not interfere), it does not remove subject 
headings entirely. Former subject headings are kept and cross-referenced to still allow for information retrieval if a patron uses an outdated term. Similarly, Melissa Adler (2016), argues that unchanged classifications and subject headings propagate systemic colonial violence by upholding colonial discourse and affecting the way in which information seekers create and internalize their own identities. Adler states that "the marginalization of 'others' in our classifications has contributed to long-term disenfranchisement and cultural imperialism" (p. 631), and that changing classification systems and library subject headings is a step towards making reparations to marginalized communities (Adler, 2016).

Although libraries could adjust classification hierarchies so that information is given a more appropriate shelf address, which would contribute to changing the ideological stories that libraries tell, the current information retrieval system that libraries use could not survive if all former subject headings were removed. David Haykin, argues that subject headings, "in wording and structure, should be that which the reader will seek in the catalog" (Drabinski, 2013, p. 101). The primary task of librarians is to provide access to information (IFLA, 2012, para. 5), and many patrons, following their own biases and knowledge limitations, may search for information using outdated terminology. Therefore, libraries can add or replace subject headings, but they cannot remove outdated terms entirely. Much like The Language of Cataloguing the ideological story that library classifications tell, these former headings tell a social and political history of language that could affect how patrons perceive and internalize their own identities. However, unlike the ideological stories that unchanged classifications tell, former subject headings still demonstrate progress towards decolonization by the very fact that they were replaced by a more socially acceptable term. The changed terminology tells a story to the patron that the previous term is no longer socially acceptable, thereby helping to deconstruct the established stereotype. But is this enough?

\section{Libraries for Social Justice}

The mission of libraries, ultimately, is to serve the public (Rubin, 2015, p. 57). Traditionally, however, public libraries had a second mission: to improve and influence society by providing more high literature than popular fiction or magazines (Rubin, 2015). Still, the survival of libraries depends on whether they can meet users' needs and remain relevant (Lor, 2016; Rubin, 2015), which means that libraries need to evolve according to societal demands and what their communities need (Rubin, 2015). Rubin (2015) explains that "the library [is] deeply embedded in the culture that created it" (p. 75), but libraries are no longer isolated to just one community the way they were when only the affluent and influential had access to information (Parent, 2015). Technological inventions, 
the Internet, and globalization have infused the missions of libraries with new meaning. Although the primary function of a librarian is to preserve information and provide access to it, globalization means that librarians are also now advocates for human rights and social justice. Where once libraries could bar undesirable patrons, for example, the lower classes prior to industrialization (Rubin, 2015), or people of African descent during slavery and segregation (Rubin, 2015), libraries must now, according to the International Federation of Library Associations and Institutions (IFLA), "recognize and acknowledge the humanity of others and... respect their rights" (2012, para. 6). This includes all people, regardless of "age, citizenship, political belief, physical or mental ability, gender identity, heritage, education, income, immigration and asylum-seeking status, marital status, origin, race, religion or sexual orientation" (IFLA, 2012, para. 15). Ethically speaking, therefore, a librarian's job is not just to preserve and provide access to information, but to also be an instrument for social justice. And this is why the language of cataloguing is so important: it is a librarian's job to work at decolonizing colonial structures so that everyone has equitable access to information (Parent, 2015).

Although librarians are supposed to remain neutral and professional when dealing with patrons, regardless of the librarian's personal opinions (IFLA, 2012), librarians should still be critical of the social structures that uphold colonial values and beliefs that contribute to the oppression of others (Farkas, 2017). Meredith Farkas (2017) explains that, "[i]n a world that is fundamentally unequal, neutrality upholds inequality and represents indifference to the marginalization of members of our community" (para. 3). Farkas (2017) argues that advocating for social justice issues means librarians should think critically about controlled vocabularies like the LCSH, which "whitewashes" (para. 3) the history of oppressed peoples by only representing "a white, male, Christian, heteronormative worldview" (para. 3). Farkas uses the subject heading "Japanese Americans-Evacuation and relocation" (2017, para. 3), for example. The words "evacuation" and "relocation" make the U.S. incarceration of Japanese-Americans in World War II sound like it was for the benefit Japanese-Americans rather than as an extreme consequence of xenophobia. If librarians are to be made accountable for their part in propagating racist ideologies, as Adler suggests, then librarians must stop viewing the subject headings in a controlled vocabulary, like the one mentioned above, as neutral. "Critical librarianship" (Lor, 2016, p. 120) is therefore about decolonizing entrenched social structures via language. The only way for librarians to truly remain neutral is to equally serve all patrons, but to do so all patrons must be equally represented. 


\section{Making Subject Headings More Inclusive}

If the language of classification cannot be fixed (in either correctness or stability), and the language of classification is also used as a means of control, what does this mean for library systems of retrieval such as the LCSH? In order to fix the ideological and colonial stories that classifications tell, Adler (2016) argues that information professionals must be held accountable and find other ways of organizing information to mitigate the marginalization of oppressed peoples. Heather Moorcroft (1993) explains that "institutional racism . . . systematically discriminates by means of language choice, system rules" (p. 30). Language choice does not always involve words, but also the absence of words, and therefore the absence of experiences of marginalized peoples (Moorcroft, 1993). This absence of words silences oppressed peoples and their histories, and removes their right to access those histories (Littletree \& Metoyer, 2015).

IFLA follows Article 19 of the United Nations Universal Declaration of Human Rights (1948), which states that all human beings have a right to access information (IFLA, 2012). Furthermore, the IFLA (2012) code of ethics states that librarians must reject censorship (government or otherwise) and any other restrictions to access. Yet the absence of marginalized communities and cultures within mainstream controlled vocabularies is a type of censorship that restricts their access

The Language of Cataloguing to information. Librarians must therefore seek out and listen to the experiences of these communities when creating representative language. This responsibility comes with its own challenges, however, because everyone has both conscious and unconscious biases due to upbringing, education, and the language that we use to categorize others outside of ourselves. When attempting to represent the other, one must therefore work at understanding and decolonizing these biases. To remove whitewashing from controlled vocabularies such as the LCSH, cataloguers should therefore be aware that they most likely have unconscious cultural biases and acknowledge them and their origins (Lor \& Britz, 2012). Cataloguers must also be aware of cultural differences and sensitivities when choosing their words in both subject headings and descriptions (Lor \& Britz, 2012), because the words that we use reflect our ideologies (Parent, 2015). Hence the development of the Subject Authority Cooperative Organization of the Program for Cooperative Cataloging (SACO). This cooperative allows multiple cataloguers to weigh in on subject heading changes in an attempt to make the language of cataloguing more inclusive (Adler, 2016). The Library of Congress, however, still has a lot of work to do before the LCSH list can truly be considered an inclusive system of information retrieval.

Although the act of representing another via language is inevitable within classification systems, it removes cultures' and individuals' authority over their own 
experiences, while also upholding and perpetuating stereotypes (Littletree \& Metoyer, 2015). The language used (or not used) in controlled vocabularies therefore impedes access to marginalized peoples and prevents them from becoming empowered by their identities (Moorcroft, 1993, p. 31). For example, a controlled vocabulary that restores authority to marginalized communities is the Mashantucket Pequot Thesaurus of American Indian Terminology Project. This project was established because of controlled vocabularies like the LCSH, which exclude American Indigenous ideologies (Littletree \& Metoyer, 2015, p. 641). Current standard subject headings are inadequate for information retrieval because they do not account for the experiences of different Indigenous groups or other marginalized peoples, so Cheryl A. Metoyer decided to create a controlled vocabulary from an Indigenous perspective (Littletree \& Metoyer, 2015). Creating subject headings from an Indigenous perspective means addressing some of the incorrect information in the LCSH. For example, the LCSH categorizes "sacred beings," legendary beings," and "sacred practitioners" under Indigenous subjects as being synonymous. As Littletree \& Metoyer (2015) explain in their article, however, these three terms have different meanings to Indigenous peoples. Controlled vocabularies or different organizational systems such as the Mashantucket Pequot Thesaurus of American Indian Terminology Project are critically important for educating information professionals and librarians about the representation of marginalized peoples and how to include them in information retrieval systems. Moreover, this project specifically works to decolonize the representation of Indigenous peoples in North America and is a good foundation for similar taxonomy projects to take place around the world.

A similar controlled vocabulary of Indigenous knowledge that will arise in the near future comes out of the Truth and Reconciliation Commission (TRC) in Canada. Camille Callison, the Indigenous representative of the Canadian Federation of Library Associations (CFLA), recently discussed the role libraries will need to play with regard to the TRC calls to action in an interview given by CBC Yukon (Librarians implement TRC calls to action, 2017). Callison explains that libraries will need to build relationships with their Indigenous communities in order to integrate Indigenous knowledges into the library system. She says this is complicated, however, because many Indigenous communities have protocols that determine access to Indigenous information. For example, certain stories can only be shared with certain people because they may belong to a specific family lineage or Indigenous group. In addition, some Indigenous stories or histories can only be shared during certain times of the year (Librarians implement TRC calls to action, 2017). Callison states that libraries must therefore integrate Indigenous knowledge into information The Language of Cataloguing 
retrieval systems in a respectful and culturally appropriate way so that Indigenous groups can access information about their culture according to how and when it is meant to be accessed (Librarians implement TRC calls to action, 2017). Ultimately, reconciliation with regards to cataloguing - whether it is the cataloguing of Indigenous or other marginalized knowledges and experiences - must come from a place of respectful cooperation and communication.

Attempting to change the ideological and colonial stories told by library classifications and subject headings also happens outside of libraries. For example, although the Library of Congress has been prevented from replacing the term "illegal alien" with something less dehumanizing, New York Times journalist Jasmine Aguilera (2016) notes that the term is being abandoned elsewhere. The Associated Press no longer refers to humans as "illegal" in its style guide, arguing that people cannot be illegal, "only actions are illegal" (Aguilera, 2016, para. 16). The Library of Congress may still be required to use "illegal alien" in its subject headings, but this does not prevent other organizations or citizens from changing their use of the term. Information professionals as a whole - not just librarians - are subject to the same ethical standards that IFLA espouses, which is equal access for all. As Littletree and Metoyer (2015) point out:

Words are powerful. The way we name and classify the world around

The Language of Cataloguing us is indicative of our values and beliefs. The words we use and the names we choose to identify elements in our world can illuminate, educate, and elucidate, or they can perpetuate stereotypes and misinformation. (p. 654)

By changing the language that we use, even when libraries cannot do so, information professionals can still have a huge impact on deconstructing stereotypes and altering socio-political discourse.

\section{Conclusion}

Ann M. Doyle (2006), states that "[t]he information industry not only acts as a gatekeeper to knowledge, it also controls the interpretation of knowledge" (as cited in Parent, 2015, p. 705). Librarians and other information professionals must keep in mind that the information they provide to others has a huge impact both on how others are viewed and how others view themselves. This ultimately comes down to the way in which words are given meaning and interpreted according to the sociopolitical climate of the time. As society, politics, and economies change, so too does the language of representation. In order for libraries to remain relevant in a changing society and to provide access to information to all cultures, groups, and individuals according to IFLA and the Human Rights Commission, librarians must always be critical of the language they are using in their information organization systems. Consequently, like language and politics, the purpose of libraries - and 
therefore of librarians - evolves. Librarians must recognize and reflect on their own internal biases when cataloguing and make it their job to deconstruct language and decolonize the systems that perpetuate the continued marginalization of others. To remain neutral about these systems is the very opposite of what it means to be a librarian in the twenty-first century.

\section{References}

Adler, M. (2016). The case for taxonomic reparations. Knowledge Organization, 43(8), 630-640.

Aguilera, J. (2016, July 22). Another word for "Illegal Alien" at the Library of Congress: Contentious. The New York Times. Retrieved from https://www.nytimes.com/2016/07/ 23/us/another-word-for-illegalalien-at-the-library-of-congresscontentious.html

Benemann, W. E. (1987, September). From Rubik's cube to designer drugs: American graffiti, library-style. American Libraries, 18(8), 650-651.

Derrida, J. (1986). Différance. In M. C. Taylor (Ed.), Deconstruction in context: Literature and philosophy (pp. 396-420). Chicago: University of Chicago Press.

Drabinski, E. (2013). Queering the catalog: Queer theory and the politics of correction. Library Quarterly:
Information, Community, Policy, 83(2), 94-111.

El-Hoshy, L. M. (1998, August). Charting a changing language with LCSH. Library of Congress Information Bulletin, 57(8), 201.

Farkas, M. (2017, January 3). Never neutral: Critical librarianship and technology. American Libraries Magazine. Retrieved from https://americanlibrariesmagazine.o rg/2017/01/03/never-neutral-critlibtechnology/

Hajibayova, L., \& Buetne, W. (2017). Representation of Indigenous cultures: Considering the Hawaiian hula. Journal of Documentation, 73(6), 1137-1148.

Hayden, C. (2017, November 18). Welcome message from Carla Hayden, $14^{\text {th }}$ librarian of congress. The Library of Congress: About the Library.

Retrieved from https://www.loc.gov/about/

International Federation of Library Associations and Institutions (IFLA). (2012, August). IFLA code of ethics for librarians and other information workers (full version). Retrieved from

https://www.ifla.org/publications/no de/11092 
Librarians implement TRC calls to action. (2017, September 19). [Radio broadcast episode]. Whitehorse, YT: Canadian Broadcasting Corporation. Retrieved from https://soundcloud.com/cbcyu kon/librarians-implement-trc-callsto-action

Library of Congress. (n.d.). SACO - Subject Authority Cooperative Program. Retrieved from https://www.loc.gov/aba/pcc/saco/

Littletree, S., \& Metoyer, C. A. (2015). Knowledge organization from an Indigenous perspective: The Mashantuket Pequot Thesaurus of American Indian Terminology Project. Cataloging \& Classification Quarterly, 53(5-6), 640-657.

Lor, P. J., \& Britz, J. J. (2012). An ethical perspective on political-economic issues in the long-term preservation of digital heritage. Journal of the American Society for Information Science and Technology, 63, 2153-2164. doi: 10.1002/asi.22725

Lor, P. J. (2016). Risks and benefits of visibility: Librarians navigating social and political turbulence. Library Trends, 65(2), 108-127.
Moorcroft, H. (1993). The construction of silence. The Australian Library Journal, 42(1), 27-32.

Parent, I. (2015). Knowledge systems for all. Cataloging \& Classification Quarterly, 53, 703-706.

Peet, L. (2016, June 13). Library of Congress drops illegal alien subject heading, provokes backlash legislation. Library Journal. Retrieved from http://j.libraryjournal.com/2016/06/ legislation/library-of-congressdrops-illegal-alien-subject-headingprovokes-backlash-legislation/\#_

Rubin, R. E. (2015). From past to present: The history and mission of libraries. In Foundations of library and information science (4th ed., pp. 31-77). New York: Neal-Schuman Publishers, Inc.

Weller, T. (2007). Information history: Its importance, relevance, and future. Aslib Proceedings, 59, 437-448. doi 10.1108/00012530710817627

White, L. (2003). Second language acquisition and universal grammar. Cambridge: Cambridge University Press. 